\title{
Prey selection of the shallow water fish Pomatoschistus minutus (Gobiidae, Teleostei) in the SW Baltic
}

\author{
C. Dieter Zander \\ Zoologisches Institut und Zoologisches Museum der Universität Hamburg; \\ Martin-Luther-King-Platz 3, D-2000 Hamburg 13, FRG
}

\begin{abstract}
The aim of this investigation is to demonstrate the reasons of an opportunist feeder to select some components of the available food supply and to avoid others. Object of this test is the eurytopic and euryhaline sand goby, Pomatoschistus minutus (Pallas), from the Luebeck Bight. It inhabits both sand habitats as well as bottoms mixed with pebbles or continuous hard substrates. Therefore, it is often in close contact with Mytilus-belts which present a very rich food supply of small crustaceans. The selectivity behaviour of sand gobies from a sand/clay ecotone was compared with that of populations from a stony pier and a sand bottom during the reproduction period. Regarding the numbers of prey organisms, crustaceans of the periphyton were generally preferred at the pier but avoided in the ecotone. The same is valid for prey organisms of the psammal which were preferred by gobies of the sand bottom but mostly avoided by populations of mixed bottoms. Analyses of size selections revealed that the preferred gammarids or Jaera isopods were between 2 and $5 \mathrm{~mm}$ length. A balanced relation of goby biomass and utilizable food supply (predatory impact index) seems to effect positive selectivity of gammarids in the Mytilus-belts or of harpacticoids in the sand bottom.
\end{abstract}

\section{INTRODUCTION}

One of the most interesting questions in prey-predator relationships is why a predator ingests more numbers or biomass of a distinct component and less or none of others, even if the prey components are present in similar quantities. Models of the optimal food spectrum of a predator indicate that the number of components is smaller in food-rich and greater in food-poor habitats (MacArthur \& Pianka, 1966). Regarding this model, a predator generally selects the most profitable prey, which means maximal energy gain combined with minimal durations of handling times (Schoener, 1971).

The feeding ecology of small-sized fish, especially gobies and sticklebacks, has increasingly become the subject of investigations in the Baltic Sea (e.g. Zander, 1979, 1988; Thorman \& Wiederholm, 1983, 1986; Evans, 1984; Pihl, 1985). These studies proved the importance of a sufficient food supply when gobies prefer distinct preys (Thorman \& Wiederholm, 1983; Zander \& Hagemann, 1987). Competition with related species may also influence selectivity (Magnhagen \& Wiederholm, 1982a) as well as the availability to the predator of prey organisms (Zander, 1979; Magnhagen \& Wiederholm, 1982b). Recent studies by Magnhagen (1986) even demonstrated the influence of the predator's activity on food choice. Nevertheless, some phenomena of prey selectivity have not yet been explained. 
The sand goby, Pomatoschistus minutus (Pallas) has already been under investigation in several feeding studies (Zander \& Hagemann, 1986, 1987; Zander, 1988, 1990). However, the question arises whether this species prefers prey organisms of distinct sizes in relation to its own body length or not. Another problem is the possible influence of the potentially available prey itself on the selectivity behaviour of the sand goby. Therefore, this study may help to reveal new knowledge on prey-predator relationships and to estimate the role of the investigated ecosystem of the Baltic Sea.

\section{INVESTIGATION SITE}

The investigation site lies off the shore below the lighthouse of Dahmeshoeved, Luebeck Bight, SW Baltic (Fig. 1). The ranges of abiotic factors during 1985 and 1986 are marked by low water temperatures in spring and high water temperatures in summer (Fig. 2). Salinity is about $10 \%$ in spring and summer, and rises to $15 \%$ and more in autumn (Fig. 2).

The sampling area next to the shore was a stony pier which runs into $3 \mathrm{~m}$ deep water. The pier was mostly covered by dense Mytilus edulis assemblages. The pier was adjoined to a sand bottom which extended to a distance of $250 \mathrm{~m}$ away from the shore. The sand was replaced in a depth of $5-6 \mathrm{~m}$ by a clay bottom which was interspersed with gravel and boulders. The hard substrates were covered by algae and mussels.

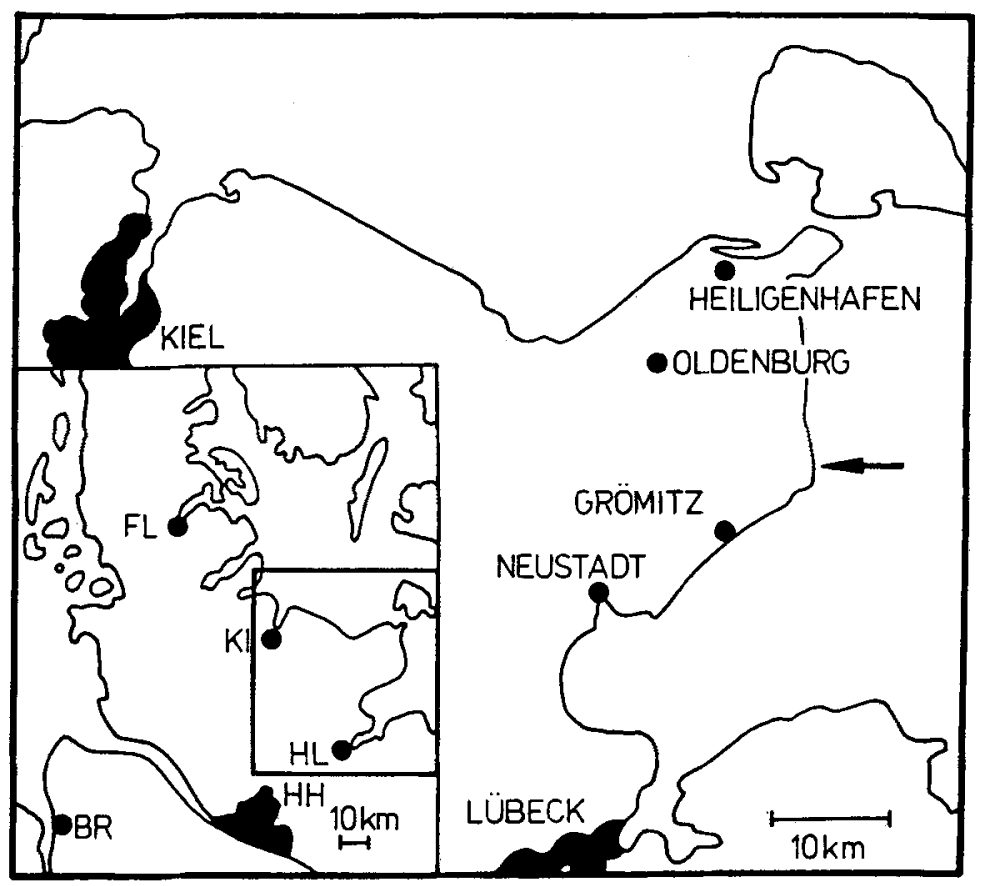

Fig. 1. Map of Schleswig-Holstein presenting the investigation site Dahmeshoeved (arrow) at the Baltic coast 


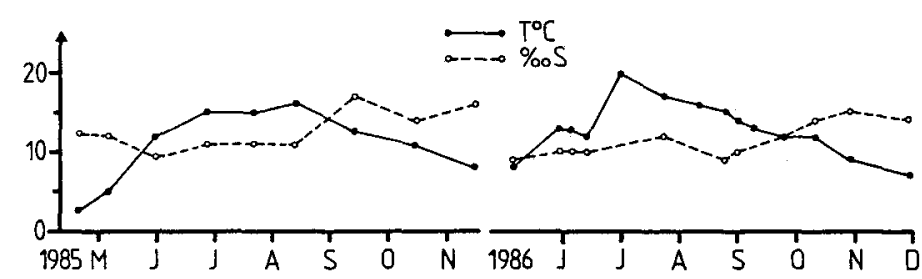

Fig. 2. Temperature and salinity data off Dahmeshoeved during the investigation time in 1985 and 1986

\section{MATERIAL AND METHODS}

Samples were taken at the pier and in the clay/sand ecotone in 1985, and in the ecotone and the adjoining sand bottom in 1986. The main object was the sand goby, Pomatoschistus minutus (Pallas). The size of mature, one-year old individuals was 55-65 $\mathrm{mm}$ total length. The fish were counted during diving (SCUBA) operations with measuring frames or ropes, comprising areas of $0.125-1 \mathrm{~m}^{2}$ (Zander, 1990). Biomass was calculated by means of the sampled specimens. A total of 502 sand gobies were caught with hand nets and later on investigated in respect to their ingested prey which comprised 6693 organisms from different taxa.

Periphyton samples from the Mytilus-belts were obtained by scratching an area of ca 12 $\mathrm{cm}^{2}$ eight times by means of the opening of a PVC-tube and collecting the organisms immediately in this tube. Samples from the sand bottom were aquired by filling the cap of a PVC-tube, comprising an area of ca $12.5 \mathrm{~cm}^{2}$, with sediment four times and pouring it into the tube.

Two indices were calculated and used in this study: (1) A "predatory impact index", named "IMP"

$$
\mathrm{IMP}=\frac{\text { Fish biomass } \mathrm{m}^{-2}}{\text { Utilizable prey biomass } \mathrm{m}^{-2}}
$$

where "utilizable prey" is that part of the supply which is sometimes ingested by the gobies (Zander \& Hagemann, 1987). (2) The selectivity index "SEL" as formulated by Berg (1979)

$$
\mathrm{SEL}=\log \frac{\% \mathrm{~N}_{\mathrm{i}} \text { in the ingested food }}{\% \mathrm{~N}_{\mathrm{i}} \text { in the available food }}
$$

\section{RESULTS}

\section{Seasonality of sand gobies and food supply}

The biomass of sand gobies was generally higher in the ecotone than at the pier in 1985 or at the sand bottom in 1986 (Fig. 3). Peak values were found in late summer due to the massive change of young gobies from the suprabenthic to the epibenthic way of life (Zander, 1990). Very low values were present in the sand bottom because this habitat was only colonized by gobies which roam about or were driven away from the ecotone when density was too high (Zander, 1990). In late autumn, the fish emigrated into deeper habitats. 

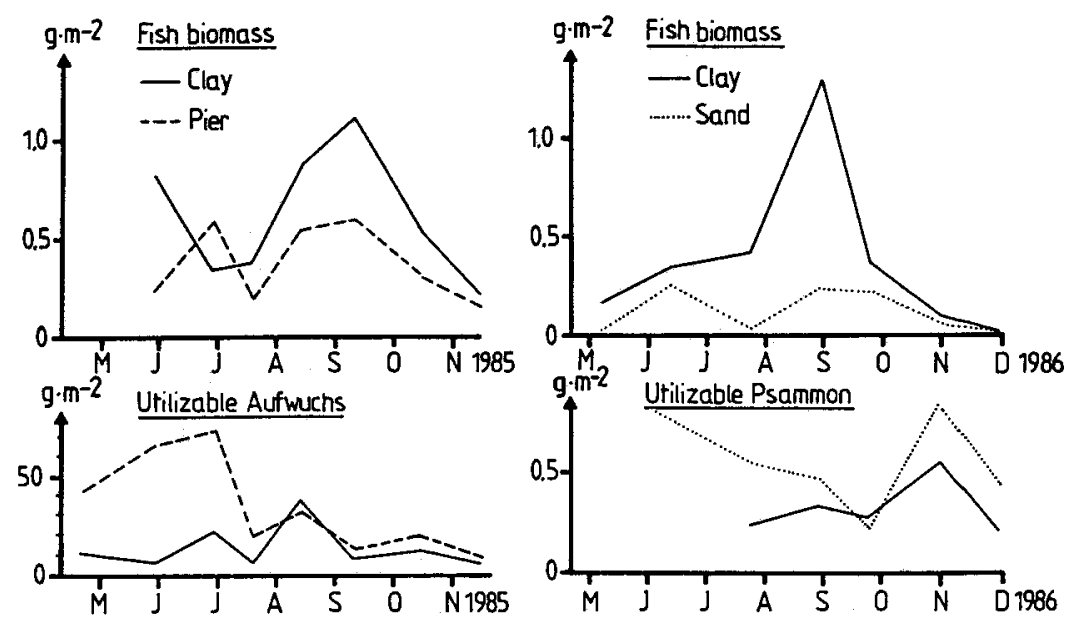

Fig. 3. Biomass of sand gobies (upper row) and biomass of utilizable food supply (lower row) in different habitats off Dahmeshoeved in 1985 (left) and 1986 (right)

The supply of utilizable phyton (aufwuchs) organisms was higher at the pier in spring 1985 but later almost similar at pier and clay ecotone (Fig. 3). The supply of psammon organisms was much lower than that of phyton. The biomass of utilizable psammon was somewhat higher in the sand bottom than in the ecotone in 1986 (Fig. 3). The values of both habitats attained minima in early autumn but peaked immediately thereafter (Fig. 3).

These results were used to calculate the IMP-index.

\section{Selectivity}

In 1985, sand gobies from the clay ecotone were compared with the population from the pier. Six components which were important as utilizable phyton were analysed (Fig. 4). In May, no case of positive selectivity - i.e. preference - was found at the pier or in the clay habitats. This result was obviously due to the intensive plankton foraging of the sand gobies at this time (Zander, 1988). Regarding the pier population, the foraging behaviour changed in the following months (Fig. 4). In summer, the gammarids, Corophium and Jaera, and sometimes also Idotea and polychaetes were clearly preferred. In autumn, this trend altered again and these components were avoided. Remarkably, the small Mytilus edulis were avoided over the whole investigation period (Fig. 4). In the clay ecotone, preference for phyton components was only seldomly found. However, a high selectivity of Idotea was present in August and a lower one in September. For gammarids there were low but positive values only in June and October, but a greater preference in November when also corophiids, Jaera and polychaetes were strongly preferred (Fig. 4). Mytilus was avoided here just as at the pier.

In 1986, the clay ecotone was compared with the sand bottom with respect to the food supply from the psammon. Here, five components were important food organisms for sand gobies, including even young Mytilus which tried to settle on the substrate (Fig. 5). In contrast to the sand gobies of the clay ecotone, the gobies of the sand bottom revealed 


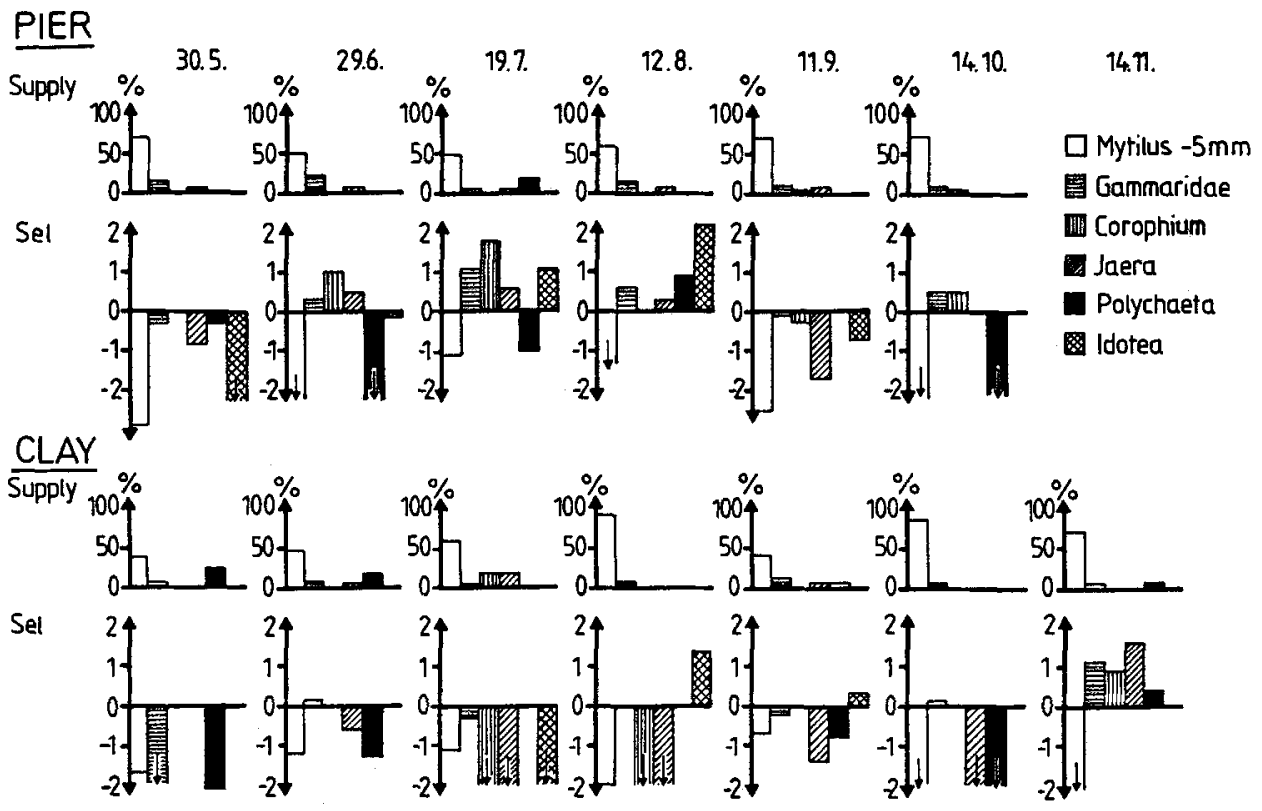

Fig. 4. Supply of 6 utilizable phyton components and their selection by sand gobies in two different habitats off Dahmeshoeved in 1985. The scale of supply means \% abundance, the scale of Sel values of the selectivity index

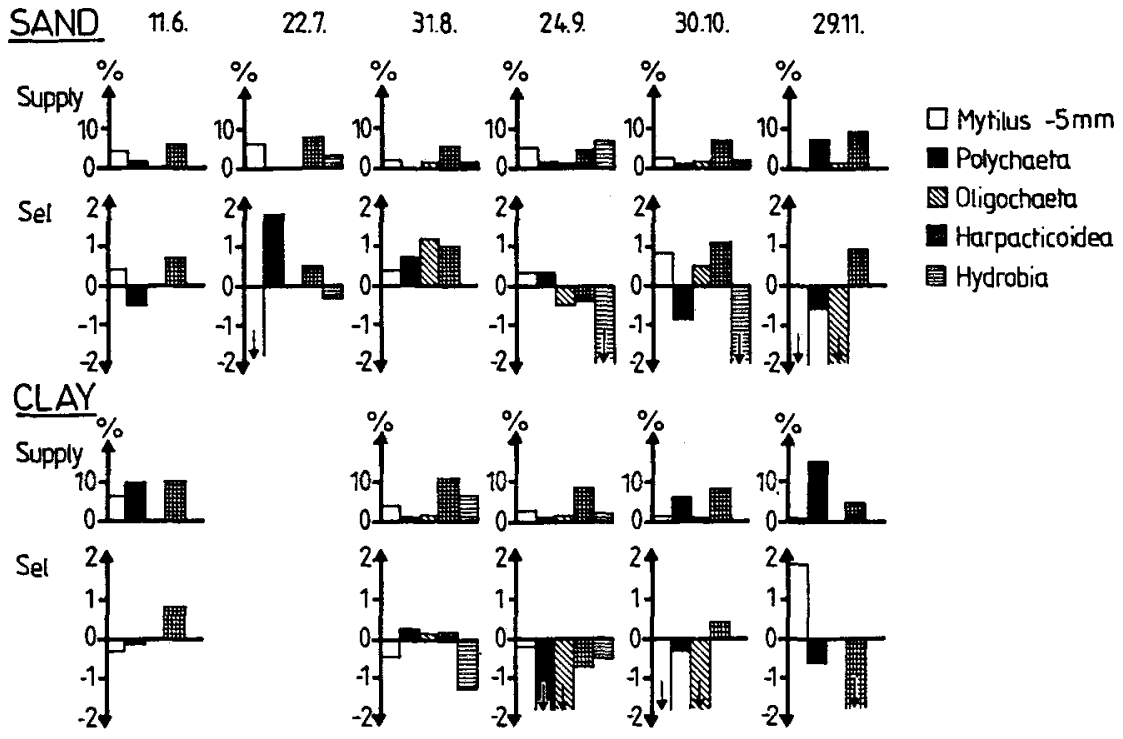

Fig. 5. Supply of 5 utilizable psammon components and their selection by sand gobies in two different habitats off Dahmeshoeved in 1986. The scale of supply means \% abundance, the scale of Sel values of the selectivity index 
a preference for all components. This might be due to the high feeding intensity of the fish. The gobies of the clay ecotone seemed to profit from the rich phyton supply because psammon components were mostly avoided (Fig. 5). The only exception were the harpacticoids which were positively selected on three dates. Unexpectedly, Mytilus were strongly preferred in November when harpacticoids were totally avoided in spite of being in sufficient supply (Fig. 5).

\section{Size selection}

The mean sizes of gammarids from the respective food supplies alternated strongly during 1985 (Fig. 6). This is also valid when individuals were compared which were caught contemporarily at the pier and in the clay ecotone, especially in May, June and July. The mean sizes of the selected gammarids were often smaller than in the supply; therefore, significant differences occurred at the pier in June, July and August (Fig. 6).

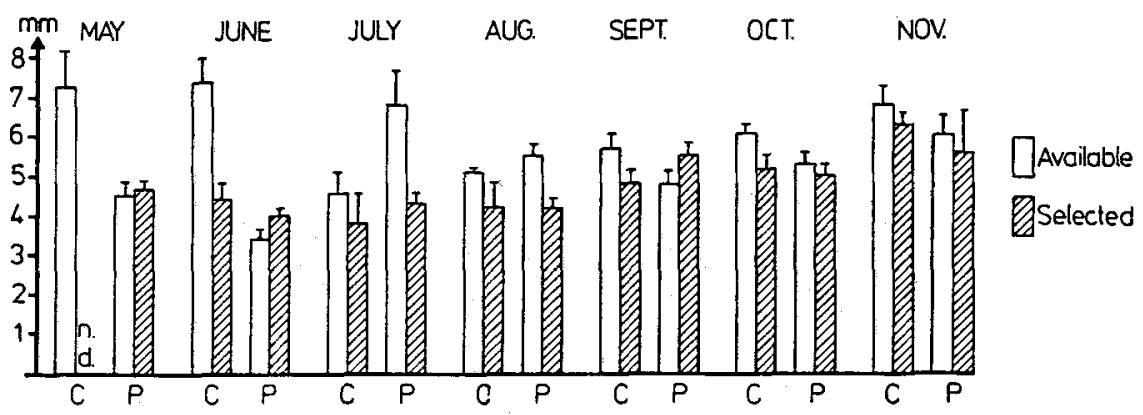

Fig. 6. Mean sizes of gammarids from the available supply and selected as food by sand gobies in two habitats off Dahmeshoeved during 1985. Bars give standard error. $\mathrm{C}=$ clay/sand ecotone; $\mathrm{P}=$ pier; n.d. $=$ no data

Regarding Jaera, only few samples from the pier contributed valuable data (Fig. 7). Whereas the size of supplied individuals varied moderately, the sizes of ingested ones were larger and very similar in every sample.

A detailed analysis regarding single size classes revealed more exact results (Fig. 8). In the clay ecotone, the 1-2 $\mathrm{mm}$ sized gammarids were preferred by gobies in summer whereas the 4-6 mm classes prevailed at other times (Fig. 8). These values were mostly conform with the composition of the supplied size classes. At the pier, mostly $3-5 \mathrm{~mm}$

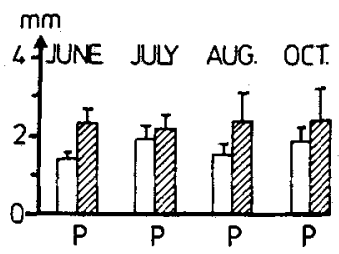

Fig. 7. Mean sizes of Jaera from the available supply and selected as food by sand gobies in the pier habitat off Dahmeshoeved during 1985. Other explanations cf. Figure 6 

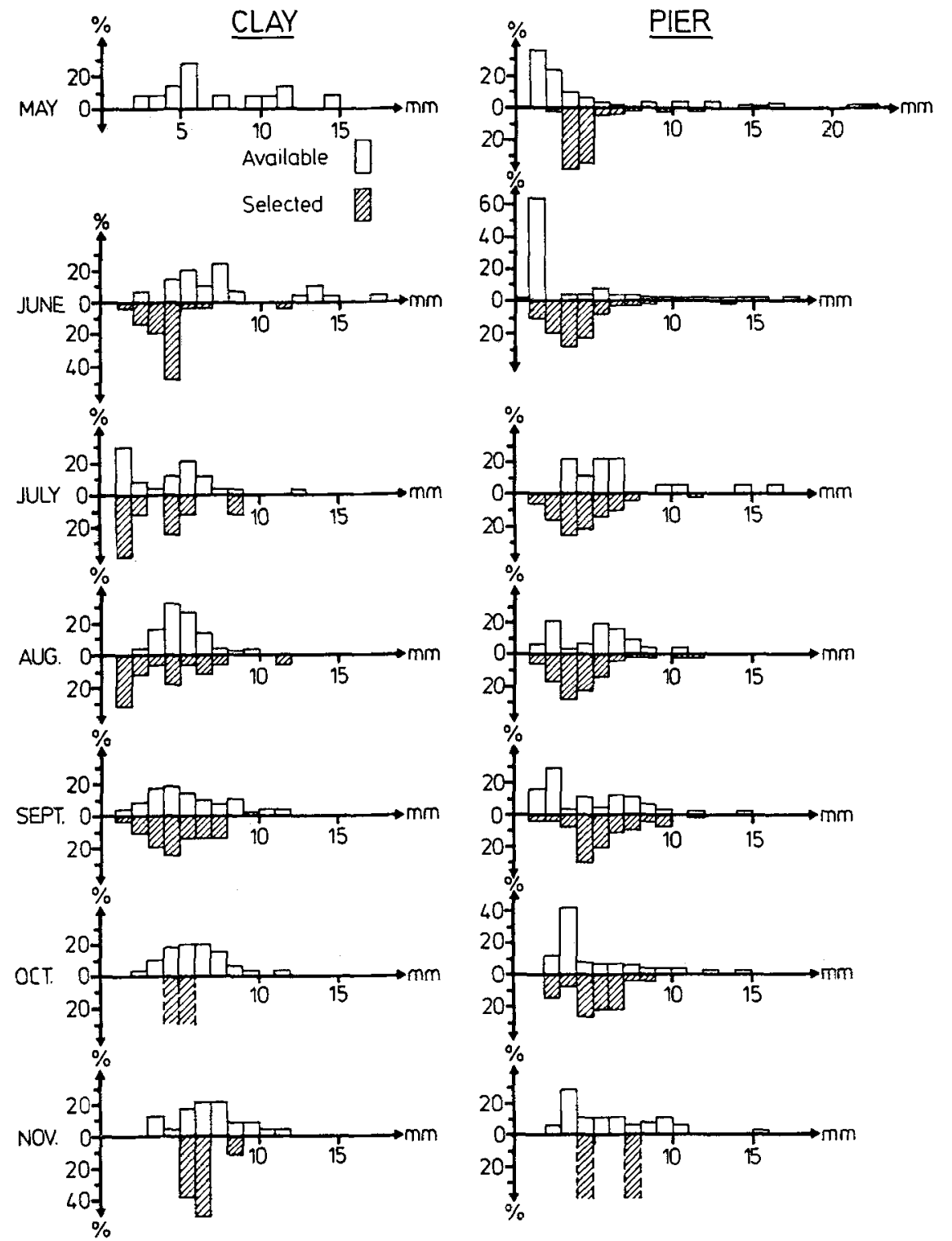

Fig. 8. Size distribution of gammarids from the available supply and selected as food by sand gobies in two habitats off Dahmeshoeved during 1985

sized gammarids were ingested. The maxima of selected and supplied organisms were seldom in accordance because the latter were often smaller (Fig. 8).

Regarding Jaera from the pier, mostly individuals of $1-2 \mathrm{~mm}$ were supplied but seldomly selected by gobies, which preferred those measuring 2-3 $\mathrm{mm}$ (Fig. 9). 


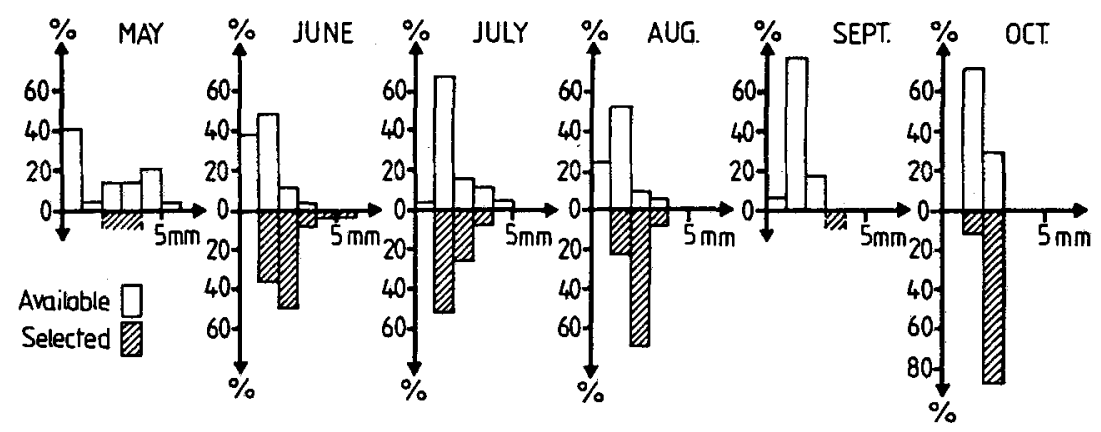

Fig. 9. Size distribution of Jaera from the available supply and selected as food by sand gobies in the pier habitat off Dahmeshoeved during 1985

\section{Size-selectivity correlations}

Selectivity as defined by Berg (1979) may depend on the biomass of the sand gobies present, and inversely on the amount of utilizable food supply. This relation is expressed by the "predatory impact index" which is correlated to the selectivity index. Regarding gammarids from the clay as well as the pier habitats a regression of the logarithmically transformed values was significant at the $5 \%$ level (Fig. 10). Remarkably, an IMP index
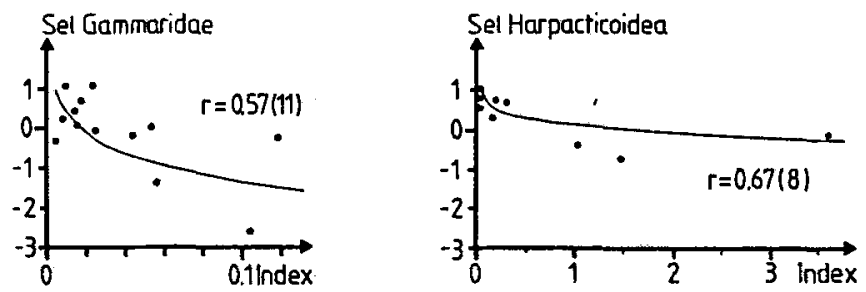

Fig. 10. Correlation of "predatory impact index" and selectivity by sand gobies regarding gammarids in 1985 (left) or harpacticoids in 1986 (right). The dates for each site are represented by dots; degrees of freedom in brackets

of less than 0.02 usually means positive selectivity, of more than 0.02 negative selectivity. The same trend is observed when the selectivity of gobies on harpacticoids in the sand bottom and the clay ecotone was analysed (Fig. 10). Due to the poor psammon supply, the index is larger than the quotient basing on the phyton supply. Therefore, positive selectivities are correlated with IMP-indices up to 0.4 on the index scale. This result was also significant at the $5 \%$ level (Fig. 10).

Other correlations were found between the sizes of selected gammarids and both the sizes as well as abundances of supplied gammarids (Fig. 11). The graphs reveal an equilibrium point at $4.5 \mathrm{~mm}$ size; below this point, ingested individuals were larger than the mean sizes of supplied gammarids; beyond it, they were smaller ( $p=5 \%)$. Regarding the relation of numbers of the gammarids in the selected size range and the size of the ingested gammarids, larger amounts led to smaller mean sizes ( $p=5 \%$ ) (Fig. 11). 

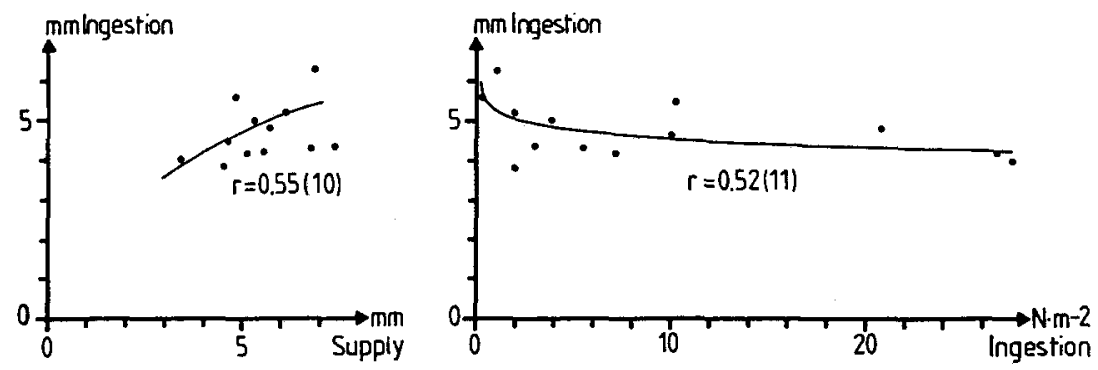

Fig. 11. Correlation of sizes of gammarids which were ingested by sand gobies and sizes of gammarids in the supply (left) or density of gammarids ingested (right). Other explanations cf. Figure 10

A corresponding analysis of Jaera-sizes presents similar results, but significance was only $10 \%$. No correlations exist between the mean sizes of gobies and sizes of ingested food components.

\section{DISCUSSION}

Selectivity of prey is a complex phenomenon which may depend on several factors. Regarding the assumptions of MacArthur \& Pianka (1966) or Schoener (1971), one can expect the predator to be able to select a distinct prey when the abundance of food supply is very high. High supply may occur due to favourable ecological factors which enhance its density or due to an increase in the biomass of the whole community which implicates an improvement for the most preferred prey organisms. This leads to the phenomena of the numerical and functional responses of a predator which means a concentration on a special prey (Holling, 1966).

Therefore, positive selectivity depends on the density of the predator, which should not be too high, and on the quantity of food supply which should be as high as possible. These two factors were combined here to form the "predatory impact index" by calculating the relation of fish biomass to supplied prey biomass. The correlations of this index with selectivity became obvious. The greater the index, the more negatively were gammarids or harpacticoids selected. This means that the main food components were supplemented more by other taxa when fish biomass increased or food supply decreased. This is very probably due to the competition which follows these two situations. Contrarily, low indices mean absence of competition which leads to positive selectivity values according to the phenomenon of functional response in the sense of Holling (1966).

Zander \& Hagemann (1987) found that $12 \%$ of gammarid but only $6 \%$ of isopod production in the SW Baltic was consumed by Pomatoschistus minutus though the production. rates were similar: 14.3 (gammarids) or $10.6 \mathrm{~g} \mathrm{~m}^{-2} \mathrm{y}^{-1}$ (isopods). The found consumption rates are therefore similar to those of $\mathrm{W}$ Swedish sand gobies which amounted to $10 \%$ of the prevailing Corophium volutator (Pihl, 1985). Magnhagen \& Wiederholm (1982a) reported also a great selectivity for Corophium by the common goby, Pomatoschistus microps, though chironomid larvae were sometimes present in equal or even higher density. However, the mentioned studies did not take the densities of fish populations into account as done in the present investigation by calculation of the 
"predatory impact index". This index seems to be a good way to judge values of selectivity because correlations become evident at a significance level of $5 \%$.

Other factors which possibly control food selection are the availability and activity of prey organisms, their sizes in relation to the predator, and the competition of the predator with other species for the respective food source. Magnhagen \& Wiederholm (1982a) found that the activity of Corophium was higher than that of chironomid larvae. Therefore, the availability of these amphipods was greater. However, the distribution of P. minutus in Dahmeshoeved does not follow the highest prey supply alone but is also influenced by other factors, such as depth, structure of bottom and presence of spawning places (Zander, 1990). Magnhagen (1986) even stressed the importance of mobility of $P$. microps during the reproductive period when the territorial males fed on more components but lesser quantities than the mobile females.

A very important result of this study was that the size of prey is not correlated with the size of the predator. This is in contrast to other studies, e.g. of Villiers (1980) or Grossman (1980). Indeed, gammarids within a range of 3-7 $\mathrm{mm}$ were here preyed on by $P$. minutus of all size classes. Zander \& Berg (1984), who analysed Mediterranean gobies and blennies, as well as Zander \& Hagemann (1987), who presented first results of Pomatoschistus species, described the same trend. In the present study, the sizes of ingested gammarids were inversely correlated with the amount of prey in the selected size range. This result may also explain the possible changes which the grazing may undergo: After an increase of the goby population, the first step is switching to smaller individuals of the selected taxon.

Due to the different foraging behaviours of fishes from the same habitat, selectivity may concern different preys. This is true when gobies were compared with sticklebacks (Zander, 1979) or blennies (Zander \& Berg, 1984). In the closely related P. minutus and $P$. microps, the choice of prey can cause segregation of the predators to different microhabitats where different prey organisms prevail (Magnhagen \& Wiederholm, 1982b).

The role of $P$. minutus in the ecosystem of Dahmeshoeved is characterized by its preference for middle- and small-sized crustaceans with relatively soft integuments. The gobies avoid mussels, snails, or oligochaetes, which are ingested only occasionally. Gammarids, which are the prevailing component, are saved to a certain degree as the gobies select the non-reproductive stages of less than $7 \mathrm{~mm}$ size (Zander \& Döring, 1989).

Acknowledgements. I wish to thank R. Fiedler and T. Hagemann for assistance during the underwater operations, P. Bernardy, K. Blohm and F. Buschmann for help in analysing the samples, M. Hänel for drawing the figures. The Deutsche Forschungsgemeinschaft supported the investigations in 1985 by a grant ( $\mathrm{Za} 44 / 6)$.

\section{LITERATURE CITED}

Berg, J., 1979. Discussion of methods of investigating the food of fishes, with reference to a preliminary study of the prey of Gobiusculus flavescens (Gobiidae). - Mar. Biol. 50, 263-273.

Evans, S., 1984. Energy budgets and predation impact of dominant epibenthic carnivores on a shallow soft bottom community at the Swedish west coast. - Estuar. coast. Shelf Sci. 18, 651-672.

Grossman, G. D., 1980. Ecological aspects of ontogenetic shifts in prey size utilization in the bay goby (Pisces: Gobiidae). - Oecologia 47, 233-238.

Holling, C. S., 1966. The functional response of invertebrate predators to prey density. - Mem. ent. Soc. Can, 48, 1-87. 
MacArthur, R. H. \& Pianka, E. R., 1966. On optimal use of a patchy environment. - Am. Nat. 100, 603-609.

Magnhagen, C., 1986. Activity differences influencing food selection in the marine fish Pomatoschistus microps. - Can. J. Fish. aquat. Sci. 43, 223-227.

Magnhagen, C. \& Wiederholm, A.-M., 1982a. Habitat and food preference of Pomatoschistus minutus and P. microps (Gobiidae) when alone and together: an experimental study. - Oikos 39 , 152-156.

Magnhagen, C. \& Wiederholm, A.-M., 1982b. Food selectivity versus prey availability: a study using the marine fish Pomatoschistus microps. - Oecologia 55, 311-315.

Pihl, L., 1985. Food selection and consumption of mobile epibenthic fauna in shallow marine areas. Mar. Ecol. Progr. Ser. 22, 169-179.

Schoener, T. W., 1971. Theory of feeding strategies. - A. Rev. Ecol. Syst. 2, 369-404.

Thorman, S. \& Wiederholm, A.-M., 1983. Seasonal occurrence and food resource use of an assemblage of nearshore fish species in the Bothnian Sea, Sweden. - Mar. Ecol. Progr. Ser. 10, 223-229.

Thorman, S. \& Wiederholm, A.-M., 1986. Food, habitat and time niches in a coastal fish species assemblage in a brackish water bay in the Bothnian Sea, Sweden. - J. exp. mar. Biol. Ecol. 95, 67-86.

Villiers, L., 1980. Changes in predation by the juvenile goby Deltentosteus quadrimaculatus (Teleostei, Gobiidae). - Neth. J. Sea Res. 14, 362-373.

Zander, C. D., 1979. On the biology and food of small-sized fish from the North and Baltic Sea areas. II. Investigation of a shallow stony ground off Møn, Denmark. - Ophelia 18, 179-190.

Zander, C. D., 1988. Zur Bedeutung von Kleinfischen in Ökosystemen der Ostsee. - Seevögel 9, 51-55.

Zander, C. D., 1990. Habitat and prey dependant distribution of sand gobies (Gobiidae, Teleostei) in the SW Baltic. - Zool. Anz. 224 (in press).

Zander, C. D. \& Berg, J., 1984. Feeding ecology of littoral gobiid and blennioid fishes of the Banyuls area (Mediterranean Sea). II. Prey selection and size preference. - Vie Milieu 34, 149-157.

Zander, C. D. \& Döring, W., 1989. The role of gobies (Gobiidae, Teleostei) in the food web of shallow habitats of the Baltic Sea. - In: Proceedings of the 21st European Marine Biology Symposium. Ed. by R. Z. Klekowski, E. Styczyńska-Jurewicz \& L. Falkowski. Polish Acad. Sci, Inst. Oceanol., Gdańsk, 499-508.

Zander, C. D. \& Hagemann, T., 1986. Fluctuations of prey, abundance and biomass of gobies (Gobiidae, Pisces) in a shallow habitat of the western Baltic Sea. - Zool. Anz. 216, 289-304.

Zander, C. D. \& Hagemann, T., 1987. Predation impact and ecological efficiency of Pomatoschistus spp. (Gobiidae, Pisces) from a clay/sand ecotone of the western Baltic Sea. - Zool. Anz. 218, $33-48$. 